\title{
Impairments of Reversal Learning and Response Perseveration after Repeated, Intermittent Cocaine Administrations to Monkeys
}

\author{
J. David Jentsch, Ph.D. ${ }^{1}$, Peter Olausson, Ph.D., Richard De La Garza, II, Ph.D. ${ }^{2}$, \\ and Jane R. Taylor, Ph.D.
}

The current experiments examined the effects of acute or repeated, intermittent administrations of cocaine on the acquisition and reversal of object discriminations by Vervet monkeys in order to test the hypothesis that cocaine treatment affects performance of tasks that depend upon the functions of the orbitofrontal cortex and amygdala. An acute dose of cocaine ( $1 \mathrm{mg} / \mathrm{kg} ; 20 \mathrm{~min}$ prior to testing) impaired reversal of a previously learned object discrimination but had no effect on acquisition of a novel one. Specific impairments of reversal learning were also observed in monkeys 9 and 30 days after repeated administrations of cocaine (2 or $4 \mathrm{mg} / \mathrm{kg}$, once daily for 14 days) that were perseverative in nature, indicating persistent behavioral consequences of repetitive dosing. The results indicate that repeated cocaine administrations produce enduring impairments of object discrimination learning when the inhibition of a previously conditioned response is required. These findings suggest that long-term cocaine administration may disrupt orbitofrontal efferents to the striatum, resulting in impaired inhibition of established conditioned responses.

[Neuropsychopharmacology 26:183-190, 2002] (C) 2002 American College of Neuropsychopharmacology. Published by Elsevier Science Inc.
KEY WORDS: Orbitofrontal cortex; Cognition; Drug addiction; Withdrawal; Stimulus-reward learning; Inhibitory control

The compulsive drug seeking and taking behavior that is characteristic of drug addiction has recently been at-

From the Department of Psychiatry, Yale University School of Medicine, New Haven, Connecticut 06508

Address correspondence to: Jane R. Taylor, Ph.D., Department of Psychiatry, Connecticut Mental Health Center, Yale University School of Medicine, 34 Park Street, New Haven Connecticut 06508, Tel.: (203) 974-7727, Fax: (203) 974-7724, E-mail: jane.taylor@yale.edu

Received January 27, 2001; revised July 23, 2001; accepted August 1, 2001.

Online publication: 8/2/01 at www.acnp.org/citations/ Npp 080201159.

${ }^{1}$ Current address: Department of Psychology, University of California at Los Angeles, P.O. Box 951563, Los Angeles, CA 90095.

${ }^{2}$ Current address: Department of Psychiatry, Albert Einstein College of Medicine, 1500 Morris Park Avenue, Bronx, New York 10461. tributed to complex, inter-related dysfunctions in neural systems mediating incentive motivation and behavioral regulation (e.g., the striatum, amygdala and ventral frontal cortex; Jentsch and Taylor 1999; Robbins and Everitt 1999; Volkow and Folwer 2000; Berke and Hyman 2000). Several lines of evidence support this hypothesis. First, drug addicts exhibit altered cerebral blood flow and metabolism within the striatum, amygdala and frontal cortex both at baseline and after drug-induced craving (c.f. Volkow and Fowler 2000; London et al. 2000). Second, chronic drug administration affects the neurochemistry and anatomy of these brain regions in animal models (Nestler and Aghajanian 1997; Robinson and Kolb 1997; Wolf 1998; Berke and Hyman 2000; Vandershuren and Kalivas 2000; Robinson et al. 2001). Third, neurobehavioral studies in humans and animals have provided evidence for abnor- 
mal locomotor and stereotypic behavior (Post et al. 1976), altered incentive motivation (Shippenberg and Heidbreder 1995; Taylor and Horger 1999; Robbins and Everitt 1999) and impaired cognitive and executive function (Jentsch et al. 1997, 2000; Rogers et al. 1999; Robbins and Everitt 1999; Grant et al. 2000; London et al. 2000; Ornstein et al. 2000) after chronic stimulant drug administration.

Because of its important role in decision-making (Bechara et al. 2000) and inhibitory control over pre-potent behavior (Roberts and Wallis 2000), an involvement of ventromedial regions of the frontal cortex in drug abuse has been proposed. In essence, impairments of frontal lobe function are thought to effectively 'un-gate' subcortically-mediated, conditioned tendencies (such as established instrumental responses to obtain and consume drugs), resulting in the compulsive drug seeking and taking that characterize addiction (Jentsch and Taylor 1999). Nevertheless, few studies have directly investigated the long-term consequences of prolonged exposure to addictive drugs on frontal cortex cognitive function, particularly in non-human primates.

The aim of the current studies was to directly evaluate the function of the prefrontocortico-amygdalo-striatal system after repeated, intermittent cocaine administrations to monkeys. Using an animal model in which drug treatment (schedule and dosing) and withdrawal can be experimentally controlled, we employed a wellcharacterized behavioral task, the acquisition and reversal of a 3-choice object discrimination. These behavioral tests allow for the examination of stimulus-reward learning (acquisition of a novel object discrimination), as well as conditioned reinforcement and inhibitory modulation of reward-related behavior (reversal learning). By employing a 3-choice object discrimination (see Arnsten et al. 1997), we can directly examine the patterns of errors made by subjects in order to determine whether, for example, responses are perseverative or random in nature. Systematic studies in monkeys with discrete cortical lesions have demonstrated that acquisition of a novel discrimination depends largely on the infero- and mesial temporal lobe (Gaffan et al. 1993), while reversal learning is additionally sensitive to orbitofrontal cortical function (Butter 1969; Gaffan et al. 1993; Dias et al. 1996). We hypothesized that repeated cocaine administrations would result in impaired reversal learning without affecting the acquisition of novel discriminations, behavioral effects that would indicate specific orbitofrontal cortical dysfunction.

\section{MATERIALS AND METHODS}

\section{Animals}

Young adult male $(\mathrm{n}=10)$ and female $(\mathrm{n}=12)$ Vervet monkeys (Cercopithecus aethiops sabaeus) were used as subjects. All animals were experimentally naive at the start of these experiments. The monkeys were housed in standard stainless steel primate cages in an open, but covered, facility at the St Kitts Biomedical Research Facility. Water was available ad libitum, while food was given in excessive amounts but only after daily testing was completed. All protocols were approved by the Yale University and St Kitts Biomedical Research Foundation animal care and use committees, and the practices and procedures employed were consistent with The Guide for the Care and Use of Laboratory Animals (National Institutes of Health).

\section{Drugs}

Cocaine hydrochloride (NIDA, Rockville MD) was dissolved in sterile saline, filtered and injected intramuscularly at a volume of $0.1 \mathrm{ml} / \mathrm{kg}$. In the acute cocaine study, monkeys were treated with saline or cocaine (1 $\mathrm{mg} / \mathrm{kg}$ ) $20 \mathrm{~min}$ prior to testing. For the repeated, intermittent cocaine studies, monkeys were treated once daily with saline $(0.1 \mathrm{ml} / \mathrm{kg})$ or cocaine $(2$ or $4 \mathrm{mg} / \mathrm{kg}$ ) for 14 days. Subjects were treated in their home cages.

\section{Object Discrimination Testing}

Testing was carried out using a modified Wisconsin General Test Apparatus that was attached to the monkey's home cage, as described by Taylor et al. (1990). The apparatus consisted of a tray with three food wells and an opaque screen, positioned between the monkey and the tray, that could be lowered and raised. All monkeys received initial habituation to the apparatus and had been trained to perform five object discriminations and three reversals prior to the experiments described in this manuscript. This allowed for all monkeys to be performing the acquisition and reversal of visual discriminations at a consistent and competent level prior to any pharmacological studies; there were no differences between the groups that went on to receive saline or cocaine prior to any drug being administered.

On each testing day, a novel set of visually distinct objects was chosen; therefore, the subjects were required to learn a new operational stimulus-reward association at the beginning of each testing session. The objects used were similar in size though the color and shape of the three objects was intentionally different. To control for overall object preferences or aversions, the object that was chosen to be the 'positive' (reward-associated) stimulus was balanced across all monkeys and treatment groups. The objects completely covered and concealed the food wells. The spatial positions of the objects were balanced across all trials, and trial order varied from day to day.

At the initiation of a testing session, the reward (a banana slice or a mini marshmallow) was hidden under 
the positive stimulus after an opaque screen was lowered between the monkey and the experimenter (the monkey was never allowed to see the reward being placed under any object). The screen was then raised, and the monkey was allowed to choose one object only (the screen was lowered if the monkey moved an object sufficiently to reveal the food well underneath). The position of the objects were then altered and the food wells were re-baited before raising the screen for the next trial. The inter-trial interval was approximately five seconds.

\section{Experiment 1: Acute Cocaine Studies}

Between-session Acquisition and Reversal. In an initial experiment, all monkeys were trained on an object discrimination in two subsequent daily sessions, each consisting of 10 trials. The monkeys were then distributed into two groups (see Table 1), and they received an injection of saline or $1 \mathrm{mg} / \mathrm{kg}$ cocaine i.m. $20 \mathrm{~min}$ prior to testing on a 20 trial session in which one of the nonreinforced stimuli from the previous two testing session was now associated with reward (reversal). 'Control' monkeys were drug naïve, having never received cocaine at any point previously during their lives. The total number of errors (choices of the incorrect objects out of 20 trials) and the total number of perseverative errors (choosing the previously reinforced stimulus) were the dependent measures.

Within-session Acquisition and Reversal. One day after being treated and tested on the between-session reversal, the monkeys were evaluated on a within-ses- sion version of the object discrimination and reversal task, as described below. The monkeys received an identical injection of cocaine or saline (the monkeys received the same treatments they had on the previous day) $20 \mathrm{~min}$ prior to testing. The cocaine-treated monkeys thus received cocaine on two consecutive days, negating our ability to eliminate multiple treatment effects, but the purpose of this study was largely to confirm the results of the between-session reversal experiment, using a within-session version.

The monkeys were first allowed to search the objects for the reward on consecutive trials, making one selection per trial. After the monkey selected the positive object and retrieved the reward, another nine trials were given with that same object-reward contingency (a total of 10 including the first selection of the positive stimulus). The number of errors out of 10 trials after the selection of the positive object (acquisition errors) was the dependent measure.

After the 10 acquisition trials, the reward was then hidden beneath only one of previously non-reinforced stimuli (the object that became the positive stimulus in the reversal phase was balanced across monkeys and treatment groups). After the monkey first selected the new positive stimulus, subsequent 19 trials were administered. The total number of selections of the previously rewarded stimulus, including both the initial search and the 20 trials under the reversed contingency, (perseverative errors) and the number of errors committed out of 20 trials after the selection of the new positive object (reversal errors) were the dependent measures.

Table 1. Monkey Information

\begin{tabular}{|c|c|c|c|c|}
\hline Monkey \# & Gender & Acute Rx & Repeated Rx & Sacrificed \\
\hline J061 & Female & Saline & Saline & After day 30 \\
\hline J053 & Female & Saline & Saline & After day 30 \\
\hline $\mathrm{J} 052$ & Female & Saline & Saline & After day 9 \\
\hline J055 & Female & Saline & Saline & After day 30 \\
\hline K010 & Female & Saline & Saline & After day 30 \\
\hline K007 & Male & Cocaine $(1 \mathrm{mg} / \mathrm{kg})$ & Cocaine $(4 \mathrm{mg} / \mathrm{kg})$ & After day 30 \\
\hline J026 & Male & Cocaine $(1 \mathrm{mg} / \mathrm{kg})$ & Cocaine $(2 \mathrm{mg} / \mathrm{kg})$ & After day 30 \\
\hline K009 & Male & Cocaine $(1 \mathrm{mg} / \mathrm{kg})$ & Cocaine $(4 \mathrm{mg} / \mathrm{kg})$ & After day 30 \\
\hline K005 & Female & Cocaine $(1 \mathrm{mg} / \mathrm{kg})$ & Cocaine $(4 \mathrm{mg} / \mathrm{kg})$ & After day 30 \\
\hline I049 & Male & Saline & Saline & After day 9 \\
\hline K003 & Female & Cocaine $(1 \mathrm{mg} / \mathrm{kg})$ & Cocaine $(2 \mathrm{mg} / \mathrm{kg})$ & After day 30 \\
\hline K008 & Female & Cocaine $(1 \mathrm{mg} / \mathrm{kg})$ & Cocaine $(2 \mathrm{mg} / \mathrm{kg})$ & After day 30 \\
\hline J040 & Female & Cocaine $(1 \mathrm{mg} / \mathrm{kg})$ & Cocaine $(4 \mathrm{mg} / \mathrm{kg})$ & After day 30 \\
\hline J065 & Female & Cocaine $(1 \mathrm{mg} / \mathrm{kg})$ & Cocaine $(4 \mathrm{mg} / \mathrm{kg})$ & After day 30 \\
\hline J049 & Male & Saline & Cocaine $(2 \mathrm{mg} / \mathrm{kg})$ & After day 30 \\
\hline J062 & Female & Saline & Cocaine $(2 \mathrm{mg} / \mathrm{kg})$ & After day 30 \\
\hline $\mathrm{J} 020$ & Male & Saline & Saline & After day 30 \\
\hline J005 & Male & Saline & Saline & After day 30 \\
\hline K021 & Male & Cocaine $(1 \mathrm{mg} / \mathrm{kg})$ & Cocaine $(4 \mathrm{mg} / \mathrm{kg})$ & After day 9 \\
\hline K011 & Male & Cocaine $(1 \mathrm{mg} / \mathrm{kg})$ & Cocaine $(2 \mathrm{mg} / \mathrm{kg})$ & After day 9 \\
\hline J032 & Male & Cocaine $(1 \mathrm{mg} / \mathrm{kg})$ & Cocaine $(4 \mathrm{mg} / \mathrm{kg})$ & After day 30 \\
\hline J066 & Female & Cocaine $(1 \mathrm{mg} / \mathrm{kg})$ & Cocaine $(2 \mathrm{mg} / \mathrm{kg})$ & After day 30 \\
\hline
\end{tabular}




\section{Experiment 2: Repeated, Intermittent Cocaine Studies}

The subjects subsequently received repeated administrations of saline, $2 \mathrm{mg} / \mathrm{kg}$ cocaine or $4 \mathrm{mg} / \mathrm{kg}$ cocaine once-daily for 14 days (see Table 1). These studies used the same subjects employed (above) in the acute drug studies; it is thus important to note that the salinetreated monkeys were those who had previously received only saline, thus still being completely cocainenaïve (Table 1). No testing was performed during the 2-week treatment period. The duration of withdrawal between drug administration and re-testing ( 9 and 30 days) was chosen in order to explore the persistence of any observed behavioral effects and the independence of these effects from possibly residual plasma or tissue levels of cocaine. Nine days after the final administration of cocaine or saline, the animals were re-tested under drug-free conditions using the within-session acquisition and reversal paradigm described above except that in these sessions, they received a total of 10 trials under the reversed contingency. A small group of monkeys was sacrificed after the day 9 testing session, so only a subset were further tested at 30 days off of the drug (see Table 1 for experimental details).

\section{Statistical Analysis}

All drug effects were determined by factorial analyses of variance (saline versus cocaine) with post hoc tests (Student Newman-Keuls) to determine levels of significance. Analyses were performed using Statview 5.0 (SAS Institute, Cary, NC). Data in the text and figures represent means + S.E.M.

\section{RESULTS}

\section{Acute Cocaine Experiments}

In the first experiment, monkeys were tested for reversal of a previously learned association (between-session reversal) $20 \mathrm{~min}$ after an acute administration of cocaine $(1 \mathrm{mg} / \mathrm{kg})$ or saline. The number of reversal errors committed out of the total of twenty trials was significantly increased in the cocaine-treated group relative to control monkeys (Figure 1, Panel A; $\mathrm{F}_{1,20}=5.06, p=.04$ ); however, there was no significant effect of treatment on perseverative errors (Figure 1, Panel A; $\left.F_{1,20}=2.27, p=.15\right)$. There were no main effects of sex or sex $X$ treatment interactions (not shown). Separate observations indicated that higher doses of cocaine ( 2 or $4 \mathrm{mg} / \mathrm{kg}$ ) resulted in animals being too stimulated to test while under the influence of the drug.

One day following the between-session reversal, the monkeys were re-treated with saline or cocaine, and they were tested on a within-session acquisition and re-
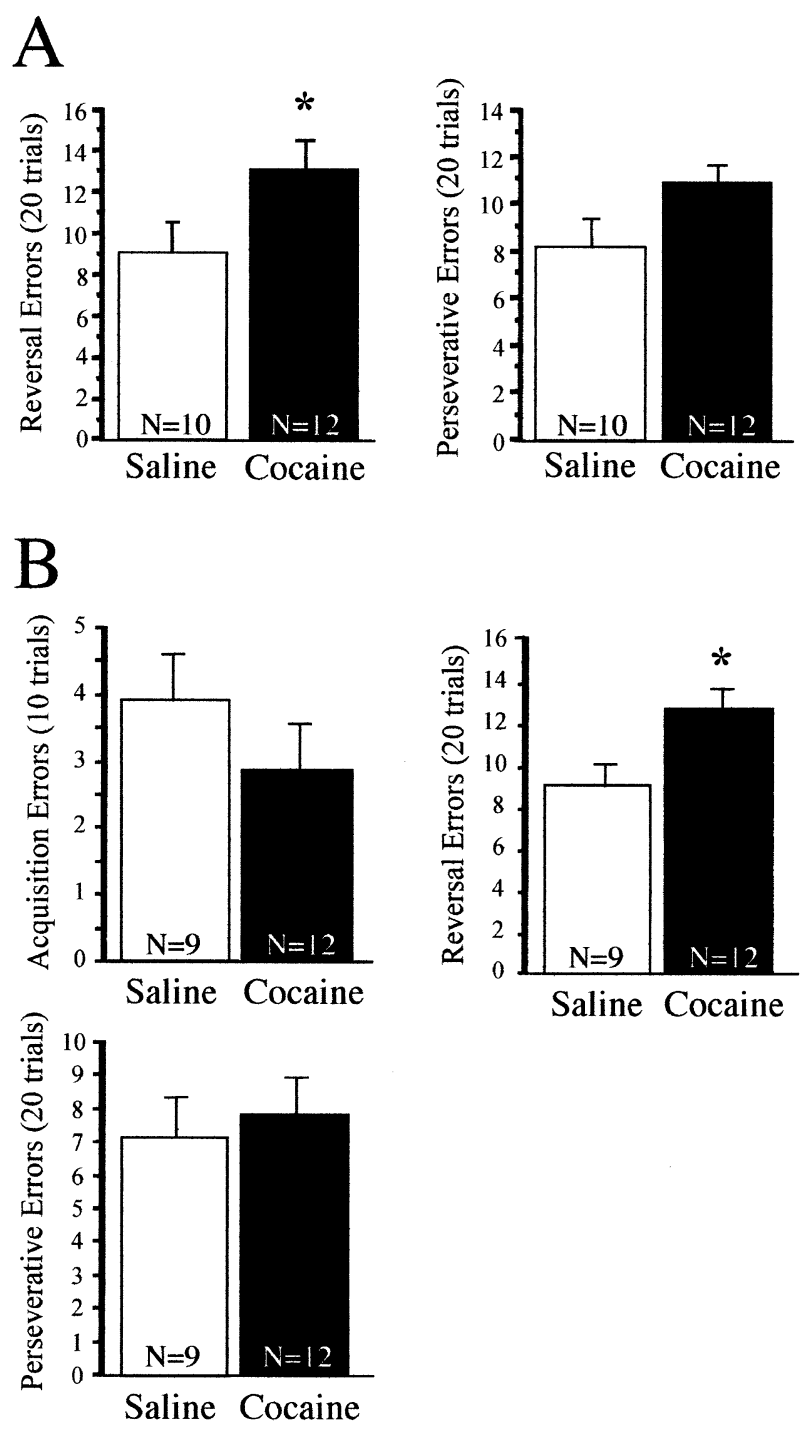

Figure 1. A. An acute dose of cocaine $(1 \mathrm{mg} / \mathrm{kg})$ impaired reversal of a previously acquired object discrimination using a between-session training paradigm. B. The selectivity of the acute cocaine-induced impairment of reversal learning was demonstrated in a second experiment in which animals acquired and reversed an object discrimination (within-session paradigm) under the effects of cocaine $(1 \mathrm{mg} / \mathrm{kg}) .{ }^{*} p<$ $.05,{ }^{* * *} p<.01$ relative to saline-treated control monkeys. Data represent means + S.E.M.

versal (one saline-treated monkey [J053] was excluded because it would not participate in the test). Acute administration of cocaine $(1 \mathrm{mg} / \mathrm{kg}$ i.m. $) 20 \mathrm{~min}$ prior to testing produced no effect on acquisition of a novel discrimination. Relative to saline, cocaine did not affect the number of acquisition errors (Figure 1, Panel B; $\left.\mathrm{F}_{1,19}=0.53, p=.48\right)$. In contrast, reversal learning was impaired by the acute administration of cocaine; reversal errors were significantly increased $20 \mathrm{~min}$ after cocaine treatment (Figure 1, Panel B; $\mathrm{F}_{1,19}=6.14, p=$ .02 ), while perseverative errors (Figure 1, Panel B; 
$\left.\mathrm{F}_{1,19}=0.004, p=.98\right)$ were not affected by cocaine treatment. There were no main effects of sex or sex $X$ treatment interactions (not shown). The first two experiments suggest that acute cocaine intoxication resulted in generally disorganized behavior during reversal, as opposed to responding specifically toward the originally reinforced stimulus.

\section{Repeated, Intermittent Cocaine Experiments}

After the acute cocaine studies, the monkeys were subsequently treated repeatedly with cocaine ( 2 or 4 $\mathrm{mg} / \mathrm{kg}$ i.m.) or saline once daily for 14 days. Nine days after the final pre-treatment, acquisition and reversal of a novel discrimination was assessed (withinsession) under drug free conditions; there were no main effects of drug treatment on acquisition errors (Figure 2; $\mathrm{F}_{2,19}=0.35, p=.71$ ), suggesting that acquisition of a novel discrimination was not affected by previous drug treatment. In contrast, there were main effects of drug treatment for the number of reversal errors (Figure 2; $\mathrm{F}_{2,19}=7.11, p=.005$ ) and perseverative errors (Figure 2; $F_{2,19}=3.56, p=.04$ ). There were no main effects of sex or sex $X$ treatment interactions (not
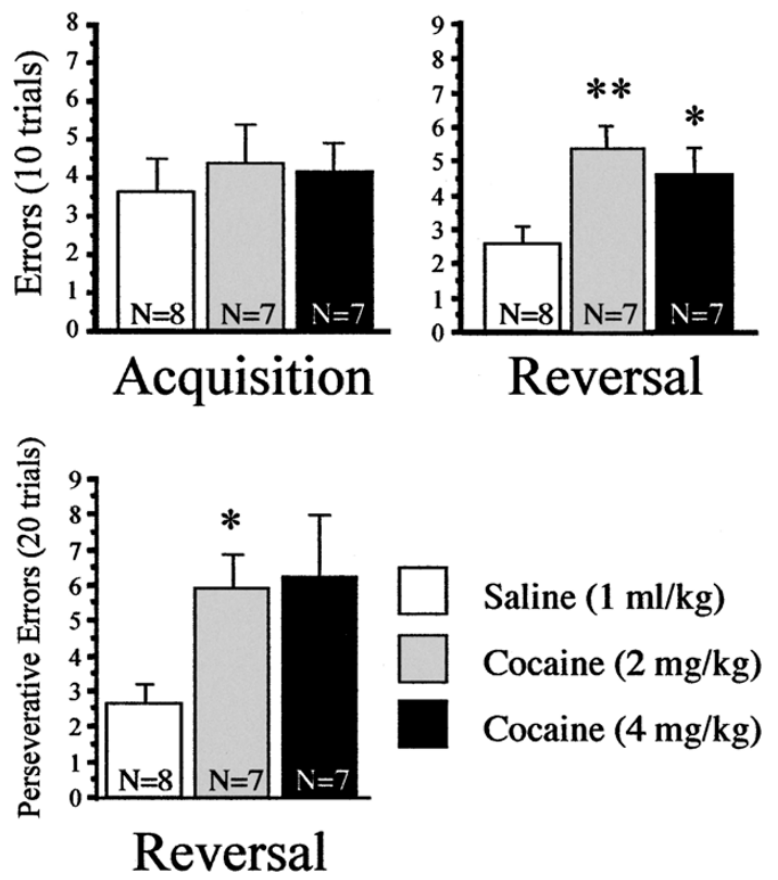

Figure 2. After nine days of withdrawal from repeated, intermittent cocaine administrations ( 2 or $4 \mathrm{mg} / \mathrm{kg}$ once daily for 14 days), monkeys exhibited selective impairments of reversal learning that were associated with significantly increased incidences of perseveration. All subjects were drug free at the time of testing. ${ }^{*} p<.05,{ }^{* *} p<.01$ relative to saline-treated control monkeys. Data represent means + S.E.M. shown). Post hoc analyses revealed that, as a group, both the 2 and $4 \mathrm{mg} / \mathrm{kg}$ cocaine monkeys exhibited increased reversal learning errors relative to the control subjects, while only the $2-\mathrm{mg} / \mathrm{kg}$ cocaine group showed statistically significant increases in perseverative errors. Four monkeys were sacrificed after the day 9 withdrawal testing session (see Table 1).

The remaining monkeys were tested again at 30 days post drug treatment; a qualitatively similar pattern of performance deficits was observed. There was no main effect of drug treatment on acquisition learning errors (Figure 3; $\mathrm{F}_{2,15}=0.27, p=.77$ ); however, analysis of variance revealed a main effect of treatment on reversal errors (Figure 3; $F_{2,15}=7.45, p=.006$ ). Post hoc analysis demonstrated that this effect was due to significantly elevated errors during reversal in the $2 \mathrm{mg} / \mathrm{kg}$ group ( $p=.005)$; a strong trend for increased errors was evident in the $4 \mathrm{mg} / \mathrm{kg}$ group ( $p=$ .07). An overall ANOVA performed to examine the effect of treatment on perseverative errors also showed a strong trend though it did not achieve statistical significance (Figure 3; $\mathrm{F}_{2,15}=3.18, p=.07$ ), possibly due to the smaller number of monkeys evaluated. Again, there were no main effects of sex or sex $X$ treatment interactions (not shown).
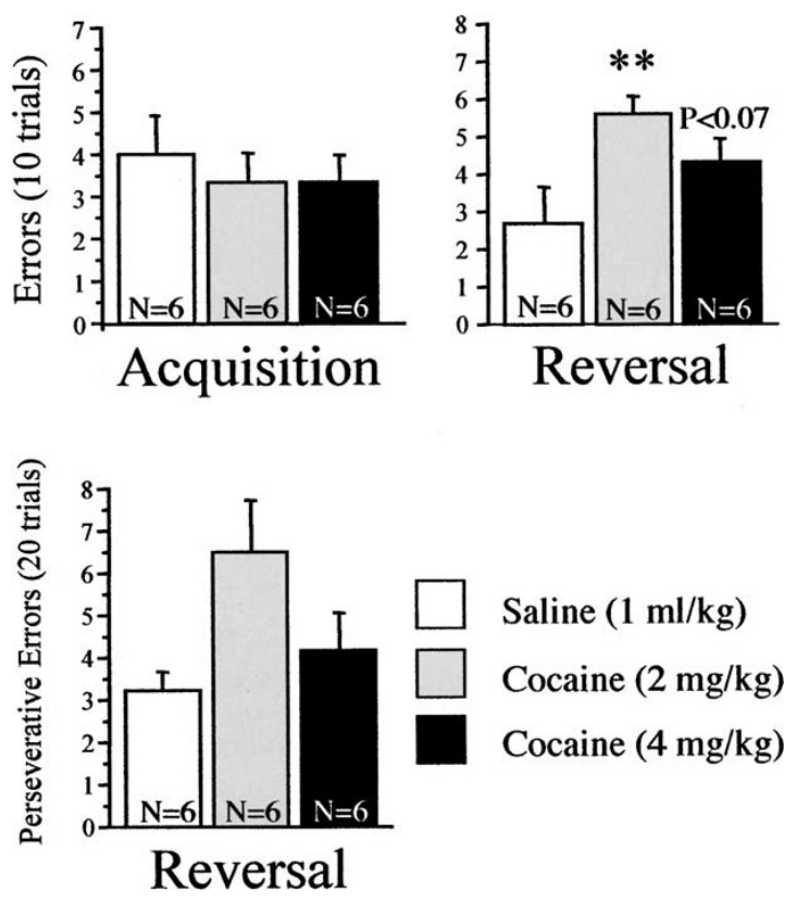

Figure 3. After 30 days of withdrawal from repeated, intermittent cocaine administrations, monkeys exhibited selective impairments of reversal learning that were associated with significantly increased incidences of perseveration. ${ }^{* *} p$ $<.05$ relative to saline-treated controls. Data represent means + S.E.M. 


\section{DISCUSSION}

The current data demonstrate persistent impairments of reversal learning in monkeys after prior repeated, intermittent administration of cocaine. Notably, repeated, intermittent cocaine treatment did not affect acquisition of a novel object discrimination. Operationally, these two conditions (reversal and novel discrimination learning) differ only in the additional need to inhibit a previously established response tendency under reversal conditions. Thus, these data suggest that monkeys treated repetitively with cocaine exhibit abnormally strong interference from previously conditioned stimulus-reward contingencies and/or an inability to inhibit this now irrelevant information in the face of new reinforcement contingencies. This interpretation is further supported by the finding that, after repeated cocaine administrations, the drug-treated animals exhibited a specifically perseverative pattern of responding, selecting the previously rewarded (now non-reinforced) object rather than the neutral object. The use of the 3-object paradigm allows us to distinguish perseverative from random responses, and the current data suggest that acute versus chronic cocaine administration can produce dissociable effects on these types of errors.

Acute treatment with cocaine also produced reversal learning deficits like repeated, intermittent treatment; however, these deficits were not necessarily perseverative in nature and effects of only one acute dose $(1 \mathrm{mg} /$ $\mathrm{kg}$ ) were studied. It remains possible that higher or lower doses would have qualitatively and/or quantitatively different effects. Of relevance, the effects of acute cocaine administration on "repeated acquisition" performance, in which monkeys are trained to produce new response chains and then modify the response sequence when contingencies subsequently change, has been explored previously. This behavioral paradigm involves components of both new learning and behavioral flexibility, similar to discrimination acquisition and reversal. Acute cocaine, across a dose range, was found to impair performance of this task (Thompson and Moerschbaecher 1979; Evans and Wenger 1992). These effects are consistent with the current (albeit limited) results indicating reversal learning impairments after administration of a single dose of cocaine $(1 \mathrm{mg} / \mathrm{kg})$.

\section{Relation to Neuropsychological Studies in Drug Addiction}

Drug addicts who predominantly abuse amphetamine, cocaine, heroin, alcohol or phencyclidine exhibit performance deficits on tasks that require response inhibition, decision making and/or cognitive flexibility (Cosgrove and Newell 1991; McKetin and Mattick 1998; O'Malley et al. 1992; Rogers et al. 1999; Ornstein et al. 2000; Grant et al. 2000). The deficits exhibited by drug abusers in- clude impairments of set shifting, planning (Ornstein et al. 2000) and decision-making (Rogers et al. 1999; Grant et al. 2000). Moreover, these deficits are relatively specific because performance of tasks that depend largely on the temporal lobe (pattern recognition, for example) is unimpaired in chronic stimulant abusers (Rogers et al. 1999; Ornstein et al. 2000). While these could be interpreted as indicating that addicts have an underlying orbitofrontal dysfunction that predisposes them to drug abuse, our results indicate that prior cocaine exposure is sufficient to produce cognitive deficits reminiscent of orbitofrontal cortical dysfunction. Therefore, the frontal lobe impairments in drug abusers may be a consequence of, as well as a pre-disposing factor to, addiction. Drug abusers often exhibit complex patterns of polysubstance abuse, as well as comorbid psychiatric and neurological disorders, which can frequently complicate experimental interpretations; however, the current data in monkeys indicates that withdrawal from even a relatively short duration of exposure to cocaine can result in behavioral impairments.

\section{Brain Lesions and Object Discrimination Performance}

Discrimination learning is affected as a result of discrete lesions of inter-related cortical and subcortical structures (Butters 1969; Gaffan et al. 1993; Dias et al. 1996; Swainson et al. 2000; Roberts and Wallis 2000). In particular, lesions of mesial temporal cortical structures, including the amygdala and entorhinal cortex, impair the acquisition of novel object discriminations by monkeys (Gaffan et al. 1993), though the degree of the behavioral impairment depends upon the method used to produce the lesion (aspiration versus excitotoxin infusion; Malkova et al. 1997). In contrast, the magnitude of the object discrimination impairment produced by orbitofrontal cortical lesions depends upon whether the discrimination to be acquired is novel or is a reversal of a previously learned association (Butters 1969; Gaffan et al. 1993; Dias et al. 1996). Specifically, orbital cortex lesions profoundly impair reversal learning while having little effect on novel discrimination acquisition. The effects of repeated cocaine administrations, reported in this study, were remarkably similar to those produced by orbitofrontal cortex lesions.

\section{Imaging Studies of Orbitofrontal Function in Drug Addiction}

In vivo imaging evidence supports a correlation between orbitofrontal dysfunction and drug addiction. Regional metabolic abnormalities within the orbitofrontal cortex and striata of drug abusers have been reported (reviewed in London et al. 2000; Childress et al. 1999; Volkow and Fowler 2000). It is noteworthy that 
the metabolic abnormalities in drug addicts occur in the brain regions that are activated by performance of setshifting, reversal learning and decision making tasks in normal humans (Rogers et al. 1999; 2000; London et al. 2000). These studies indicate that interactions between cortical and subcortical regions are likely implicated in the psychopathology produced by drug intake and would support the notion that the impairments of reversal learning reported here may involve components of altered stimulus-reward learning, conditioned reinforcement and inhibitory control of rewarded responses (Jentsch and Taylor 1999).

\section{Pharmacological Implications of Orbitofrontal- Striatal Dysfunction in Addiction}

The hypothesis of frontal dysfunction in drug abuse is consistent with several therapies that may be effective treatments for drug addiction. For example, Self and colleagues (1996) found that dopamine D1 receptor agonists can reduce drug-seeking behavior in a self-administration paradigm. Given the relative enrichment of dopamine D1 receptors in the frontal cortex (Bergson et al. 1995) and the failure of intra-accumbens D1 agonist infusions to produce similar effects (Karanian et al. 1999), it may be that systemic administration of the D1 agonist is acting within cortical regions to modulate impaired gating of striatal function. These results are consistent with the cognitive effects produced by administration of D1 agonists in a variety of behavioral paradigms (Zahrt et al. 1997; Cai and Arnsten 1997; Granon et al. 2000). Moreover, a partial dopamine D3 receptor agonist has been shown to reduce cocaineseeking behavior (Pilla et al. 1999), and these receptors are highly enriched in the ventral striatum (Diaz et al. 1995). Animal models of frontostriatal dysfunction in drug addiction may be used to evaluate the neurochemical bases of the frontal lobe dysfunction, as well as to evaluate the pharmacological responsivity of frontal lobe impairments in drug-treated subjects. The application of these methods in non-human primates is especially warranted given the limited homology between the rodent and primate and human frontal cortices.

\section{Summary}

These studies are the first indication that repeated administrations of cocaine to monkeys is sufficient to produce a form of orbitofronto-striatal dysfunction similar to that reported in drug addiction. Repetitive administrations of cocaine to monkeys produced impairments of reversal learning that persist even after cessation of drug administration. Additional studies may indicate how drug-induced changes in cortical neuron morphology (Robinson and Kolb 1997; Robinson et al. 2001), signal transduction mechanisms (Nestler and Aghajanian
1997), cortical-subcortical physiological interactions (Onn and Grace 2000) or excitatory amino acid and monoaminergic neurotransmission (Wolf 1998; Robbins and Everitt 1999; Berke and Hyman 2000; Vanderschuren and Kalivas 2000) contribute to this form of addiction-related psychopathology.

\section{ACKNOWLEDGMENTS}

The authors thank Eric Nestler for insightful discussions and support, Victoria Stewart and Valyphone Phantharangsy for technical assistance and the staff of the St Kitts Biomedical Research Foundation for animal care support. These studies were supported by PHS Grants DA11026 and DA11717.

\section{REFERENCES}

Arnsten AFT, Lin CH, Van Dyck CH, Stanhope KJ (1997): The effects of 5-HT3 receptor antagonists on cognitive performance in aged monkeys. Neurobiol Aging 18:21-28

Bechara A, Damasio H, Damasio A (2000): Emotion, decision making and the orbitofrontal cortex. Cereb Cortex 10: 295-307

Bergson C, Mrzljak L, Smiley J, Pappy M, Levenson R, Goldman-Rakic PS (1995): Regional, cellular and subcellular variations in the distribution of the D1 and D5-dopamine receptors in primate brain. J Neurosci 15:7821-7836

Berke JD, Hyman SE (2000): Addiction, dopamine and the molecular mechanisms of memory. Neuron 25:515-532

Butter CM (1969): Perseveration in extinction and in discrimination reversal following selective frontal ablations in Macaca mulatta. Physiol Behav 4:163-171

Cai JX, Arnsten AFT (1997): Dose-dependent effects of the dopamine D1 receptor agonists A77636 or SKF81297 on spatial working memory in aged monkeys. J Pharmacol Exp Ther 283:183-189

Childress AR, Mozley PD, McElgwin W, Fitzgerald J, Reivich M, O'Brien CP (1999): Limbic activation during cueinduced cocaine craving. Am J Psychiatry 156:11-18

Cosgrove J, Newell TH (1991): Recovery of neuropsychological functions during reduction in use of phencyclidine. J Clin Psychol 47:159-169

Dias R, Robbins TW, Roberts AC (1996): Dissociation in prefrontal cortex of affective and attentional shifts. Nature 380:69-72

Diaz J, Levesque D, Lammers CH, Griffon N, Martres MP, Schwartz JC, Sokoloff P (1995): Phenotypical characterization of neurons expressing the dopamine D3 receptor in the rat brain. Neuroscience 65:731-745

Evans EB, Wenger GR (1992): Effects of drugs of abuse on acquisition of behavioral chains in squirrel monkeys. Psychopharmacology 107:55-60

Gaffan D, Murray EA, Fabre-Thorpe M (1993): Interaction of the amygdala with the frontal lobe in reward memory. Eur J Neurosci 5:968-975

Granon S, Passetti F, Thomas KL, Dalley JW, Everitt BJ, Robbins TW (2000): Enhanced and impaired attentional per- 
formance after infusions of D1 dopaminergic receptor agents into rat prefrontal cortex. J Neurosci 20:1208-1215

Grant S, Contoreggi C, London ED (2000): Drug abusers show impaired performance of a laboratory test of decision making. Neuropsychologia 38:1180-1187

Jentsch JD, Redmond DE, Elsworth JD, Taylor JR, Youngren KD, Roth RH (1997): Enduring cognitive deficits and cortical dopamine dysfunction in monkeys after long-term administration of phencyclidine. Science 277:953-955

Jentsch JD, Taylor JR (1999): Impulsivity resulting from frontostriatal dysfunction in drug abuse: Implications for the control of behavior by reward-related stimuli. Psychopharmacol 146:373-390

Jentsch JD, Roth RH, Taylor JR (2000): Impaired performance of an object retrieval/detour task by monkeys after subchronic phencyclidine administration: Evidence for cognitive impulsivity. Biol Psychiatry 48:415-424

Karanian DA, Schimdt EF, Self DW (1999): Effects of intraaccumbens infusions of D1 and D2 dopamine receptor agonists on relapse to cocaine-seeking behavior. Soc Neurosci Abstr 25:1071

London ED, Ernst M, Grant S, Bonson K, Weinstein A (2000): Orbitofrontal cortex and human drug abuse: Functional imaging. Cereb Cortex 10:334-342

Malkova L, Gaffan D, Murray EA (1997): Excitotoxic lesions of the amygdala fail to produce impairment in visual learning for auditory secondary reinforcement but interfere with reinforcer devaluation effects in rhesus monkeys. J Neurosci 17:6011-6020

McKetin R, Mattick RP (1998): Attention and memory in illicit amphetamine users: Comparison with non-drugusing controls. Drug Alcohol Dep 50:181-184

Nestler EJ, Aghajanian GK (1997): Molecular and cellular basis of addiction. Science 278:58-63

O'Malley S, Adamse M, Heaton RK, Gawin FH (1992): Neuropsychological impairment in chronic cocaine abusers. Am J Drug Alcohol Abuse 18:131-144

Onn SP, Grace AA (2000): Amphetamine withdrawal alters bistable states and cellular coupling in rat prefrontal cortex and nucleus accumbens neurons recorded in vivo. J Neurosci 20:2332-2345

Ornstein TJ, Iddon JL, Baldacchino AM, Sahakian BJ, London M, Everitt BJ, Robbins TW (2000): Profiles of cognitive dysfunction in chronic amphetamine and heroin abusers. Neuropsychopharmacology 23:113-126

Pilla M, Perachon S, Sautel F, Garrido F, Mann A, Wermuth CG, Schwartz JC, Everitt BJ, Sokoloff P (1999): Selective inhibition of cocaine-seeking behaviour by a partial dopamine D3 receptor agonist. Nature 400:371-375

Post RM, Kopanda RT, Black KE (1976): Progressive effects of cocaine on behavioral and central amine metabolism in rhesus monkeys: Relationship to kindling and psychosis. Biol Psychiatry 11:403-419

Robbins TW, Everitt BJ (1999): Drug addiction: Bad habits add up. Nature 398:567-570

Roberts AC, Wallis JD (2000): Inhibitory control and affective processing in the prefrontal cortex: Neuropsychological studies in the common marmoset. Cereb Cortex 10:252-262

Robinson TE, Kolb B (1997): Persistent structural modifications in nucleus accumbens and prefrontal cortex neurons pro- duced by previous experience with amphetamine. J Neurosci 17:8491-8497

Robinson TE, Gorny G, Minon E, Kolb B (2001): Cocaine selfadministration alters the morphology of dendrites and dendritic spines in the nucleus accumbens and neocortex. Synapse 39:257-266

Rogers RD, Everitt BJ, Baldacchino A, Blackshaw AJ, Swainson R, Wynne K, Baker NB, Hunter J, Carthy T, Booker E, London M, Deakin JFW, Sahakian BJ, Robbins TW (1999): Dissociable deficits in the decision-making cognition of chronic amphetamine-abusers, opiate abusers, patients with focal damage to prefrontal cortex and tryptophan-depleted normal volunteers: Evidence for monoaminergic mechanisms. Neuropsychopharmacology 20:322-339

Rogers RD, Andrews TC, Grasby PM, Brooks DJ, Robbins TW (2000): Contrasting cortical and subcortical activations produced by attentional-set shifting and reversal learning in humans. J Cog Neurosci 12:142-162

Self DW, Barnhart WJ, Lehman DA, Nestler EJ (1996): Opposite modulation of cocaine-seeking behavior by D1- and D2-like dopamine receptors. Science 271:1586-1589

Shippenberg TS, Heidbreder C (1995): Sensitization to the conditioned rewarding effects of cocaine: pharmacological and temporal characteristics. J Pharmacol Exp Ther 273:808-815

Steere JC, Arnsten AFT (1997): The alpha-2 noradrenergic receptor agonist guanfacine improves visual object discrimination reversal performance in aged rhesus monkeys. Behav Neurosci 111:883-891

Swainson R, Rogers RD, Sahakian BJ, Summers BA, Polkey CE, Robbins TW (2000): Probabilistic learning and reversal deficits in Parkinson's disease or frontal or temporal lobe lesions: Possible adverse effects of dopaminergic medication. Neuropsychologia 38:596-612

Taylor JR, Elsworth JD, Roth RH, Sladek JR, Redmond DE (1990): Cognitive and motor deficits in the acquisition of an object retrieval/detour task in MPTP-treated monkeys. Brain 113:617-637

Taylor JR, Horger BA (1999): Enhanced responding for conditioned reward produced by intra-accumbens amphetamine is potentiated after cocaine sensitization. Psychopharmacology 142:31-40

Thompson DM, Moerschbaecher JM (1970): An experimental analysis of the effects of d-amphetamine and cocaine on the acquisition and performance of response chains in monkeys. J Exp Anal Behav 32:433-444

Vanderschuren LJ, Kalivas PW (2000): Alterations in dopaminergic and glutamatergic transmission in the induction and expression of behavioral sensitization: A critical review of preclinical studies. Psychopharmacology 151:99-120

Volkow ND, Fowler JS (2000): Addiction, a disease of drive and compulsion: Involvement of the orbitofrontal cortex. Cereb Cortex 10:318-325

Wolf ME (1998): The role of excitatory amino acids in behavioral sensitization to psychomotor stimulants. Prog Neurobiol 54:679-720

Zahrt J, Taylor JR, Mathew RG, Arnsten AFT (1997): Supranormal stimulation of D1 dopamine receptors in the rodent prefrontal cortex impairs spatial working memory performance. J Neurosci 17:8528-8538 